\title{
COMPARISON OF SCREENING TESTS FOR METALLO-BETA-LACTAMASE PRODUCING GRAM NEGATIVE BACTERIA
}

\author{
Niranjan. H. P, Priyanka. B. V, Basavarajappa. K. G, Jayasimha. V. L
}

1. Assistant Professor, Department of Microbiology, SSIMS \& RC, Davangere- 577005

2. III Year MBBS student, SSIMS \& RC, Davangere- 577005

3. Professor, Department of Microbiology, SSIMS \& RC, Davangere- 577005

4. Associate Professor, Department of Microbiology, SSIMS \& RC, Davangere- 577005

\section{CORRESPONDING AUTHOR:}

Dr. Niranjan. H. P,

Assistant Professor,

Department of Microbiology,

SSIMS \& RC, Davangere- 577005.

E mail ID- niranjanhp@gmail.com

\begin{abstract}
:
BACKGROUND: The wide spread dissemination of metallo-beta-lactamase (MBL) resistance to carbapenem antibiotics, such as Imipenem (IMP) and other antibiotics, among gram negative pathogens have become a global concern. The present study is to evaluate various screening tests to determine Metallobetalactamase production. OBJECTIVES: 1)To determine the frequency of metallo-beta-lactamases among Imipenem and ceftazidime resistant isolates 2)To evaluate four phenotypic tests for detection of metallo-beta-lactamase. MATERIALS AND METHODS: A total of 48 clinical isolates from various samples showing resistance to imepenem and ceftazidime were screened for MBL production by 4 different methods 1)Imepenem with Ethylene-Diamine-Tetra-Acetic acid ( EDTA) combined disc test,2)EDTA disc potentiation test with imepenem,3) EDTA disc potentiation test with ceftazidime and 4)ceftazidime with EDTA combined disc test, and compared . RESULTS: In the present study, Of the 48 isolates tested, 34(70.83\%) were positive for MBL production by at least one of the methods used. Pseudomonas aeruginosa was the predominant organism producing MBL 18(52.94\%) followed by Klebsiella pneumoniae $4(11.76 \%)$.EDTA disc potentiation test with imepenem was the most sensitive method 28(82.35\%). CONCLUSION: In the present study, Imepenem with EDTA, both combined and double disc potentiation tests were more effective than ceftazidime with EDTA. Though there are several screening methods recommended for detection of MBL production, no single test when used alone is specific for these enzymes.
\end{abstract}

KEY WORDS: Imipenem, Carbapenem, combined disc test, Metallo-Beta-Lactamase, EDTA.

\section{INTRODUCTION:}

The wide spread dissemination of metallo-beta-lactamase (MBL) resistance to carbapenem antibiotics, such as Imipenem (IMP), among gram negative pathogens have become a global concern ${ }^{1}$. The metallo-beta-lactamase belongs to group B beta-lactamases which require divalent cations as co-factor for their activity, being inhibited by the action of a metal ion chelator. The MBLs hydrolyze all beta-lactams except Aztreonam in vitro 2 .The present study Journal of Evolution of Medical and Dental Sciences/Volume 1/Issue 2/April-June 2012 
is to detect the MBL in gram negative bacilli from various clinical samples. Four different screening methods were used to determine their effectiveness.

\section{MATERIALS AND METHODS:}

A total of 48 clinical isolates from (ICU, NICU, MICU, SICU) of S.S. Hospital, showing resistance to Imipenem and Ceftazidime were tested for metallo-beta-lactamase enzyme production by 4 methods:-

1) Imipenem-EDTA combined disc test: - Test organisms were inoculated onto MullerHinton agar. One 10 micro gm Imipenem disc and one commercially available Imipenem $(10 \mu \mathrm{g})$-EDTA $(750 \mu \mathrm{g})$ combined disc was placed on the inoculated plates and incubated at $35^{\circ} \mathrm{C}$ for $16-18 \mathrm{hrs}$. The inhibition zones were compared. In the combined disc, if the increase in the inhibition zone was more than $7 \mathrm{~mm}$ than the Imipenem disc alone, it was considered MBL positive ${ }^{3}$.

2) EDTA disc potentiation test using Imipenem:- Test organisms were inoculated on Muller-Hinton agar. Two Imipenem 10 micro gm discs were placed $4 \mathrm{~cm}$ apart and a blank filter paper disc $(6 \mathrm{~mm})$ (Whatman no.2) was placed $1 \mathrm{~cm}$ near one disc to which 5 micro litre of $0.5 \mathrm{M}$ EDTA solution was added ${ }^{3}$. Isolates which showed clear larger zone of inhibition around Imipenem disc towards EDTA were considered as MBL producers ${ }^{4}$.

3) Ceftazidime-EDTA combined disc test: - Test organisms were inoculated onto MullerHinton agar. Two 30 micro gm Ceftazidime discs were placed $4 \mathrm{~cm}$ apart and 5 micro litre of 0.5M EDTA was added to one of the disc. The inhibition zones were compared. In the combined disc, if the increase in the inhibition zone was more than the Ceftazidime disc alone, it was considered MBL positive ${ }^{3}$.

4) EDTA disc potentiation test using Ceftazidime: - Test organisms were inoculated on Muller-Hinton agar. Two Ceftazidime 30 micro gm discs were placed $4 \mathrm{~cm}$ apart and a blank filter paper disc $(6 \mathrm{~mm})$ (Whatman no.2) was placed $1 \mathrm{~cm}$ near one disc to which 5 micro litre of 0.5M EDTA solution was added ${ }^{3}$. Isolates which showed clear larger zone of inhibition around Ceftazidime disc towards EDTA were considered as MBL producers ${ }^{4}$.

\section{RESULTS:}

In the present study, most common age group affected was <10 years $10(29.41 \%)$ and males were more frequently affected 22 (64.71\%). 
Table 1: Shows age and sex distribution of MBL positive:

\begin{tabular}{|l|l|l|l|}
\hline \multirow{2}{*}{ Age in years } & \multicolumn{2}{|l|}{ Sex } & \multirow{2}{*}{ Total ( in \%) } \\
\cline { 2 - 3 } & Male & Female & \\
& & & \\
\hline$<10$ years & 6 & 4 & $10(29.41 \%)$ \\
\hline $11-20$ years & 4 & 2 & $6(17.65 \%)$ \\
\hline $21-30$ years & 6 & 2 & $8(23.53 \%)$ \\
\hline $31-40$ years & 4 & 2 & $6(17.65 \%)$ \\
\hline $41-50$ years & 2 & 2 & $4(11.76 \%)$ \\
\hline TOTAL & $22(64.71 \%)$ & $12(35.29 \%)$ & $34(100 \%)$ \\
\hline
\end{tabular}

Table 2: Shows bacteria producing MBL:

\begin{tabular}{|l|l|}
\hline Organism & Number (percentage) \\
\hline Pseudomonas. Aeruginosa & $18(52.94 \%)$ \\
\hline Klebsiella pneumoniae & $4(11.76 \%)$ \\
\hline Klebsiella oxytoca & $2(5.88 \%)$ \\
\hline Acinetobacter spp. & $4(11.76 \%)$ \\
\hline Citrobacter spp. & $4(11.76 \%)$ \\
\hline Non-fermenters & $2(5.88 \%)$ \\
\hline TOTAL & $34(100 \%)$ \\
& \\
\hline
\end{tabular}

In the present study, $34(70.83 \%)$ isolates were positive for MBL production by one or more screening methods and the most sensitive method of MBL detection was Imepenem with EDTA disc potentiation test.

Table 3: Shows comparison of screening test in MBL detection:

\begin{tabular}{|l|l|}
\hline Screening test & Number(percentage) \\
\hline $\begin{array}{l}\text { EDTA disc potentiation test with } \\
\text { imepenem }\end{array}$ & $28(82.35 \%)$ \\
\hline Imepenem with EDTA combined disc test & $14(41.18 \%)$ \\
\hline $\begin{array}{l}\text { EDTA disc potentiation test with } \\
\text { ceftazidime }\end{array}$ & $12(35.29 \%)$ \\
\hline Ceftazidime with EDTA combined disc test & $13(38.24 \%)$ \\
\hline
\end{tabular}

Journal of Evolution of Medical and Dental Sciences/Volume 1/Issue 2/April-June 2012 


\section{DISCUSSION:}

Carbapenems are presently considered as the most potent agents of treatment of multidrug resistant gram negative bacterial infections. However, recently there have been reports of increased resistance to this in Pseudomonas aeruginosa. Resistance to carbapenems may develop due to impermeability, which occurs due to the loss of Opr D porins , the regulation of an active efflux system in these organisms, or the production of MBL's5. Production of MBL by gram negative bacteria has tremendous therapeutic consequences, since they have limited treatment options. In the present study, 48 Imipenem and Ceftazidime resistant strains from different clinical samples from ICU, MICU, SICU and NICU were subjected to screening tests for MBL production.

In the present study, the most common age group affected was $<10$ years 10 (29.4\%). Males 22 (64.71\%) were more frequently affected than females, with male: female ratio being 1.83:1. Deeba $B$ et al in their study has reported that male: female ratio was 1.2:1 and the most common age group was $>60$ years $(46.6 \%)$.This could be due to more number of patients in the age group of less than 10 years in the present study and small sample size.

In the present study most common organisms producing MBL was P.aeruginosa (52.94\%) followed by K.pneumoniae (11.76\%), Acinetobacter spp(11.76\%) and Citrobacter spp (11.76\%), which is comparable with the studies of Debasrita Chakraborty et al ${ }^{7}$ and Lee $\mathrm{K}$ et $\mathrm{al}^{8}$.

In the present study, out of the 48 isolates resistant to Imepenem and Ceftazidime tested, 34 were positive for MBL production by one or more of the screening methods. Imepenem with EDTA double disc potentiation test was the most sensitive 28 (82.35\%) in our study followed by Imepenem+ EDTA combined disc test 14 (41.18\%), where as many other studies have shown imepenem+EDTA combined disc test as most sensitive and some of the studies have shown both IMP and CTZ with EDTA as equally effective tests. This variation could be due to small differences in the commercially available EDTA and in house prepared EDTA.

\section{CONCLUSION:}

To conclude, Pseudomonas aeruginosa is the predominant organism producing MBL. Our study found Imipenem with EDTA both combined and double disc potentiation tests more effective than Ceftazidime with EDTA. Currently no standardised method for MBL detection has been proposed and despite PCR being accurate and reliable, its accessibility is often limited to reference laboratories. Though there are several screening methods recommended for detection of MBL production, no single test when used alone is specific for these enzymes. Further studies are required to evaluate the various screening methods for the detection of MBL in order to correctly use them conveniently.

\section{REFERENCES:}

1. Tan J, Pitout J and Guttman D. Metallo beta lactamase detection using Imipenem with EDTA. J of Clin. Microbiol; May 2008; 46(5): 1870-72.

2. Hemalatha V, Umashekar \& Kamat V. Detection of metallo betalactamase producing Pseudomonas aeruginosa in hospitalized patients. Indian J Med Res; 2005; 122: 148-52.

Journal of Evolution of Medical and Dental Sciences/Volume 1/Issue 2/April-June 2012 
3. Bhalerao DS, Roushani S, Kinikar AG, Akhter I. Study of Metallo-beta lactamase producing Pseudomonas aeruginosa in Pravara Rural Hospital. Med Rev 2010; 5(3).

4. Mendiratta DK, Deotale V \& Narang P. Metallo-beta-Lactamase producing Pseudomonas aeruginosa in hospital from rural area. Indian J Msed Res; May 2005; 121: 701-3.

5. Nordmann P, Poirel L. Emerging Carbapenemases in gram negative aerobes. Clin. Microbiol. Infect 2002; 8:321- 31.

6. Deba B et al. Detection of metallo-betalactamase producing P.aeruginosa at a tertiary care hospital in Kashmir. Afr. J. Microbiol. Res; 2011: 5(2): 164-72.

7. Debsrita $\mathrm{C}$ et al.Study of infections caused by metallobetalactamase producing gram negative bacteria in the intensive care patients . American journal of Infectious diseases ; 2010; 6(2): 349.

8. Lee $\mathrm{K}$ et al. Evaluation of Hodge test and Imipenem-EDTA diouble disk synergy test for differentiating metallo B-lactamase producing isolates of Pseudomonas spp and as Acinetobacter spp. J. clin. Microbiol. 2003; 41 (10):4623-29. 